\title{
PENGEMBANGAN MODUL BERBASIS DAERAH TRENGGALEK UNTUK MENUMBUHKAN SIKAP PEDULI LINGKUNGAN
}

\author{
Kardiana Metha Rozhana 1), Moh. Farid Nurul Anwar 2) \\ PGSD, Universitas Tribhuwana Tunggadewi, Indonesia \\ jr.kardiana@yahoo.com, mohfaridnurulanwar@gmail.com
}

\begin{abstract}
The teacher's difficulties in teaching are weaknesses in preparing thematic lesson plans and the lack of adequate learning resources for students. The purpose of this development and research is to provide facilities and new innovations for elementary school teachers in developing module teaching materials. The hope is that this module can be used as an additional supplement for students and as an effort to apply environmental awareness as found in character education. This study used the research and development method of Borg \& Gall. The results of the feasibility validation from the experts showed that the percentage of $89.4 \%$ was feasible. While aspects of the application of teachers and students of module products through questionnaires showed an average percentage of $92.5 \%$ with very good criteria and could be used without revision. While the effectiveness of modules is seen from two aspects, namely learning outcomes with a mean percentage of $95.2 \%$ showing complete learning and learning activities showing active information with a percentage of $77.4 \%$. While the value of environmental care attitude shows a percentage of $3 \%$, namely a good attitude towards the environment of residence.
\end{abstract}

Keywords: Module, Trenggalek Area, Attitude Caring

\begin{abstract}
Abstrak
Kesulitan guru dalam mengajar yaitu kelemahan dalam menyusun RPP tematik dan kurangnya sumber belajar yang memadahi bagi siswa. Tujuan pengembangan dan penelitian ini yaitu memberikan kemudahan dan inovasi baru bagi guru SD dalam mengembangkan bahan ajar modul. Harapannya modul ini dapat dijadikan suplemen tambahan bagi siswa dan sebagai upaya menerapkan sikap peduli lingkungan sebagaimana yang terdapat dalam pendidikan karakter. Penelitian ini menggunakan metode penelitian dan pengembangan Borg \& Gall. Hasil validasi kelayakan dari para ahli menunjukkan persentase $89,4 \%$ layak digunakan. Sedangkan aspek keterterapan guru dan siswa produk modul melalui angket menunjukkan persentase rata-rata 92,5\% dengan kriteria sangat baik dan dapat digunakan tanpa revisi. Sedangkan keefektifan modul dilihat dari dua aspek yaitu hasil belajar dengan persentase rerata 95,2\% menunjukkan pembelajaran tuntas dan aktivitas belajar menunjukkan keterangan aktif dengan persentase 77,4\%. Sedangkan nilai sikap peduli lingkungan menunjukan persentase $3 \%$ yaitu sikap baik terhadap lingkungan tempat tinggal.
\end{abstract}

Kata Kunci: Modul, Daerah Trenggalek, Sikap Peduli Lingkungan

\section{PENDAHULUAN}

Upaya guru dalam mengajar harus terus ditingkatkan sesuai dengan karakteristik dan lingkungan tempat tinggal siswa. Guru dituntut untuk kreatif dan inovatif dalam mengemas pembelajaran baik sebelum maupun saat proses membelajarkan materi kepada siswa. Hal ini merupakan tantangan guru di era millenial dimana kreatifitas diutamakan dalam menyusun pembelajaran pada kurikulum 2013 yang sifatnya teks bacaan sehingga suplemen lain perlu dikembangkan. Salah satu upaya untuk membelajarkan siswa yaitu pengembangan modul berbasis daerah tempat tinggal siswa. Modul merupakan 
bahan ajar yang dirancan dan disesuaikan dengan kebutuhan siswa baik karakteristik dan lingkungan tempat tinggal serta mengulas informasi penting dan diakhiri dengan pemberian soal. Modul yang disusun yaitu modul tematik dengan mengintegrasikan beberapa muatan di dalamnya. Tematik merupakan konsep menggabungkan beberapa muatan bidang studi yang dijadikan dalam satu kesatuan tema. Menurut Fogarty (1991) pembelajaran tematik merupakan pembelajaran bersifat terpadu yang mengaitkan berbagai bidang studi, tema-tema yang mengundang konsep dari berbagai bidang study.

Modul yang dikembangkan dalam penelitian ini yaitu modul berbasis Daerah Trenggalek karena penelitian dan pengembangan dilaksanakan di SD tersebut. Beberapa faktor yang mempengaruhi dikembangkannya modul ini yaitu sekolah berada di pelosok sehingga kurang masuknya informasi baru, guru kesulitan dalam mengembangkan RPP kurikulum 2013, siswa lemah informasi terkait potensi yang dimiliki daerahnya, dan kurangnya sumber belajar. Untuk memenuhi hal tersebut modul ini dikemas dengan mengutamakan daerah tempat tinggal siswa. Daerah Trenggalek kaya akan SDA baik pertanian dan perkebunannya, memiliki destinasi wisata, budaya lokal, dll. Hal tersebut harus dijaga kelestraiannya agar dapat dinikmati oleh generasi selanjutnya. Menurut Anderson \& Krathwohl (2001) dengan karakteristik siswa di setiap wilayah Indonesia yang berbeda-beda, maka perlu adanya identifikasi unsur budaya lokal dalam mengalaman belajar bermakna siswa. Hal yang dapat dilakukan yaitu mengmabngkan bahan ajar modul tematik untuk memberikan pengalaman bermakna bagi siswa yang dikemas dengan menarik, menyenangkan, dan berkelanjutan. Pembelajaran tematik yang meaningful dan joyfull dapat terwujud melalui mengaitkan materi pembelajaran dengan dunia terdekat siswa atau biasa dikenal dengan contextual teaching and learning (Utari Unga, dkk, 2016:40). Hal serupa dengan pendapat Trianto dalam Prastowo (2014) bahwa pembelajaran tematik sebagai pembelajaran yang dirancang berdasarkan tema-tema.

Penyusunan modul berbasis daerah Trenggalek ini selain memberikan wawasan kepada siswa terkait kekayaan yang dimiliki daerahnya juga meyelipkan nilai karakter. Nilai karakter yaitu suatu nilai baik yang diiringi dengan melakukan hal-hal yang dapat dipertanggungjawabkan. Karakter menentukan pikiran pribadi seseorang dan tindakan seseorang yang baik adalah motivasi ke dalam untuk melakukan apa yang benar, menurut standar perilaku tertinggi dalam setiap situasi (Wanda Chrisiana, 2005). Tujuannya untuk membiasakan siswa memiliki perilaku yang baik sesuai dengan norma masyarakat dalam menjaga lingkungan tempat tinggalnya. Sikap peduli lingkungan merupakan perilaku positif dalam mencintai, menghargai, dan merawat lingkungan agar dapat dinikmati generasi penerus.

Hakikat sikap peduli lingkungan dapat duraikan dalam pengertian dasar pada setiap kata yaitu terdiri dari tiga kata kunci yaitu sikap, peduli dan 
lingkungan. Pertama kata sikap, dalam KBBI sikap diartikan sebagai perbuatan, gerak gerik ataupun perilaku. Kedua yaitu kata peduli dalam KBBI peduli dapat diartikan juga mengindahkan, menghiraukan dan memperhatikan. ketiga kata lingkungan dalam KBBI memiliki arti daerah atau kawasan, wilayah, golongan atau kalangan dan semua yang memengaruhi pertumbuhan manusia dan hewan. Jadi sikap peduli lingkungan adalah suatu perbuatan atau perilaku yang memperhatikan kedaan suatu wilayah ataupun daerah tertentu yang dapat mempengaruhi keadaan wilayah tersebut. Pendidikan yang berkaitan tentang karakter peduli lingkungan diharapkan dapat mengubah sikap positif terhadap lingkungan dan sekolah sebagai sarana mengajarkan sikap tersebut (Kresnawati, 298:2013). Menurut Nenggala (2007:173) indikator seseorang yang peduli lingkungan yaitu: 1) Menjaga kelestarian lingkungan sekitar, 2) Tidak mengambil, menebang atau mencabut tumbuh-tumbuhan di sepanjang perjalanan, 3) Tidak mencoret-coret, menorehkan tulisan pada pohon, batu-batu, jalan atau dinding, 4) Membuang sampah pada tempatnya, 5) Tidak membakar sampah di sekitar perumahan, 6) Melaksanakan kegiatan membersihkan lingkungan, 7) Menimbun barang-barang bekas, dan 8) Membersihkan sampah-sampah yang menyumbat saluran air.

\section{METODE}

Penelitian ini menggunakan metode penelitian dan pengembangan (Research and Development) menurut Borg \& Gall (1983:772) yaitu suatu proses yang digunakan untuk mengembangkan dan memvalidasi produk-produk yang dikembangkan dan terdapat proses mengembangkan dan menguji kelayakan dan keefektifan suatu produk dengan kriteria yang disesuaikan dengan produk yang telah dikembangkan. Penelitian ini dilaksanakan pada bulan September-Desember 2018 di SDN 2 Pringapus yang beralamatkan di RT 39/08 Desa Pringapus Kecamatan Dongko Kabupaten Trenggalek kelas IV sebanyak 15 siswa. Penulis berperan aktif dalam proses pembuatan modul dan penerapan modul untuk mendapatkan hasil yang valid. Pengembangan dan penelitian ini menggunakan tahap pengembangan model Borg \& Gall yang disederhanakan menjadi sembilan tahapan ditunjukkan pada gambar 1.

Jenis data yang diperoleh dari hasil uji coba produk pengembangan modul berbasis Potensi Kabupaten Trenggalek dibagi menjadi dua jenis. Pertama berupa data kuantitatif yang diperoleh dari instrumen pengumpulan data dan kualitatif dari saran-saran perbaikan yang diberikan para ahli validasi. Instrumen pengumpulan data yang digunakan pada penelitian pengembangan ini yaitu instrument validasi tentang kelayakan aspek isi/materi, bahasa, desain, keterterapan dan keefektifan hasil belajar serta aktivitas belajar. 


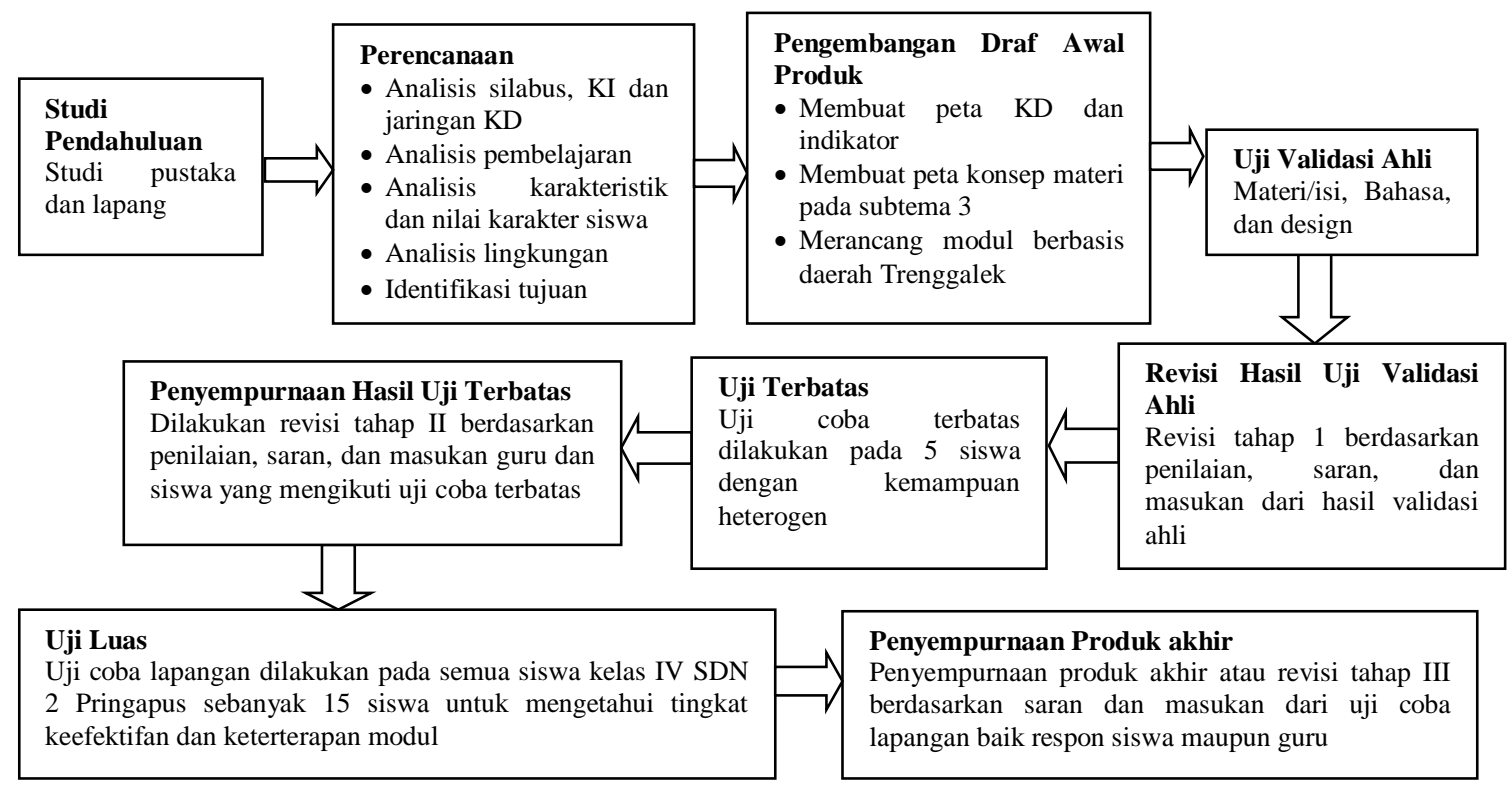

\section{Gambar 1. Pengembangan Model Modifikasi Borg\&Gall}

Teknik analisis data yang digunakan yaitu reduksi data untuk merangkum data dan membuang data yang tidak perlu, Penyajian data diperoleh dari hasil angket uji ahli isi/materi, bahasa, desain, guru, dan siswa, dan penarikan kesimpulan yaitu tahap akhir proses analisis setelah melakukan reduksi dan penyajian data. Untuk mengetahui nilai siswa digunakan data keefektifan dari aktivitas dan hasil belajar siswa selama menggunakan modul. Teknik analisis data dapat dilihat pada tabel sebagai berikut.

Tabel 1. Aspek yang Dinilai

\begin{tabular}{lllll}
\hline \multicolumn{1}{c}{ Aspek } & \multicolumn{1}{c}{ Data } & Instrumen & Data yang diamati & \multicolumn{1}{c}{ Responden } \\
\hline $\begin{array}{l}\text { Kelayakan } \\
\text { Produk }\end{array}$ & Ahli & Lembar & Kelayakan Produk & $\bullet$ Ahli Desain \\
& & Angket & Modul (1) & $\begin{array}{l}\text { • Ahli Materi } \\
\bullet \text { Ahli Bahasa }\end{array}$ \\
\cline { 2 - 5 } & Keterterapan & Angket & Produk Modul (2) & $\begin{array}{l}\bullet \text { Guru Kelas } \\
\text { • Siswa }\end{array}$ \\
\cline { 2 - 5 } & Keefektifan & Lembar Tes & Hasil Belajar Siswa (3) & Siswa \\
\cline { 2 - 5 } & Produk & Lembar & Aktivitas Siswa (4) & Siswa \\
\hline $\begin{array}{l}\text { Sikap Peduli } \\
\text { Lingkungan }\end{array}$ & Sikap & Observasi & & Siswa \\
\hline
\end{tabular}

\section{HASIL DAN PEMBAHASAN}

Pendidikan memiliki peranan yang penting untuk menentukan perkembangan serta mewujudkan pribadi individu melalui proses pembelajaran di kelas (Rozhana, 2017:198). Melalui modul yang dikembangkan berbasis potensi Kabupaten Trenggalek dapat meningkatkan perkembangan siswa dalam pembelajaran. Beberapa potensi meliputi aspek ekonomi, budaya, teknologi informasi dan komunikasi, ekologi, hasil bumi, kreasi seni, tradisi, budaya, pelayanan, jasa, SDA, dan SDM. Keunggulan tersebut haruslah dijaga 
keberadaanya sehingga dapat dinikmati oleh generasi penerus bangsa. Tujuan dikembangkannya modul berbasis potensi Kabupaten Trenggalek yaitu agar siswa mengetahui kekeyaaan alam yang ada di sehingga mampu menumbuhkan rasa bangga terhadap lingkungan tempat tinggal dan mampu menjaga kelestarian lingkungan. Ahmadi (2012:10) menyatakan bahwa tujuan adanya pendidikan berbasis keunggulan lokal yaitu siswa mengetahui, memahami, kemudian siswa mampu mengolah sumber daya alam, terlibat dalam pelayanan atau jasa atau kegiatan lain yang berkaitan dengan keunggulan lokal, sehingga memperoleh penghasilan dan melestarikan budaya atau tradisi maupun sumber daya. Berikut data yang diperoleh selama penelitian dengan mengembangkan modul berbasis daerah Trenggalek dengan disisipkan muatan karakter.

Tabel 2. Rekapitulasi Hasil Kelayakan

\begin{tabular}{clc}
\hline No & \multicolumn{1}{c}{ Aspek } & Skor (\%) \\
\hline 1 & Uji Ahli Materi Ahli & 96,8 \\
\hline 2 & Uji Ahli Bahasa & 90,5 \\
\hline 3 & Uji Ahli Desaign & 80,8 \\
\hline \multicolumn{2}{c}{ Jumlah } & 268,1 \\
\hline & Rata-rata & $\mathbf{8 9 , 4} \%$ \\
\hline
\end{tabular}

Selain memberikan penilaian secara kuantitatif, ahli materi, bahasa, dan design memberikan saran untuk perbaikan modul yang telah dikembangkan, saran dari ahli materi yaitu dalam materi kurang memberikan soal terkait muatan karakter, gambar yang digunakan sebaiknya hasil dokumentasi sediri namun jika tidak terjangkau dapat mengambil dari internet disertai sumber langsung, penulisan kurang komunikatif bagi siswa SD, dan sebaiknya mengembangkan nilai karakter lainnya. Namun dalam hal ini modul berfokus pada peduli lingkungan sehingga tidak diberikan muatan lagi dan saran lain diperbaiki. Untuk ahli bahasa yaitu bahasa sudah baku dan mudah dimengerti siswa SD. Sedangkan dari ahli design yaitu jangan terlalu mengkombinasikan warna di setiap halaman, cetak dengan kualitas bagus agar gambar tidak pecah, tata letak tulisan dan gambar sebaiknya diperhatikan agar seimbang, dan cover sebaiknya menampilkan lingkungan daerah Trenggalek.

\section{Tabel 3. Hasil Angket Keterterapan}

\begin{tabular}{lcc}
\hline No & Aspek & Skor (\%) \\
\hline 1 & Angket Siswa & 94,6 \\
\hline 2 & Angket Guru & 90,4 \\
\hline & Jumlah & 185 \\
\hline & Rata-rata & $\mathbf{9 2 , 5 \%}$ \\
\hline
\end{tabular}

Guru kelas juga memberikan saran agar modul dapat digunakan dengan baik. Guru memberikan saran agar modul di cetak glossy agar gambar bagus dan modul tahan lama, dapat digunakan jangka panjang. Dalam buku siswa guru menyisipkan ajakan siswa untuk menjaga lingkungan atau gambar-gambar animasi cara menjaga lingkungan sekitar tempat tinggal. 
Tabel 4. Hasil Nilai Tes (Keefektifan Hasil Belajar Siswa)

\begin{tabular}{ccccccccc}
\hline No & P 1 & P 2 & P 3 & P 4 & P 5 & P 6 & Jumlah & Rata-rata \\
\hline 1 & 100 & 98 & 90 & 100 & 90 & 98 & 576 & 96 \\
\hline 2 & 100 & 70 & 98 & 88 & 80 & 100 & 536 & 89,3 \\
\hline 3 & 90 & 76 & 80 & 100 & 98 & 100 & 544 & 90,7 \\
\hline 4 & 88 & 90 & 100 & 98 & 100 & 100 & 576 & 96 \\
\hline 5 & 98 & 98 & 95 & 100 & 88 & 98 & 577 & 96,2 \\
\hline 6 & 100 & 100 & 100 & 100 & 98 & 100 & 598 & 99,7 \\
\hline 7 & 98 & 100 & 100 & 100 & 98 & 92 & 588 & 98 \\
\hline 8 & 93 & 90 & 96 & 100 & 98 & 100 & 577 & 96,2 \\
\hline 9 & 80 & 98 & 100 & 90 & 100 & 100 & 568 & 94,7 \\
\hline 10 & 83 & 70 & 80 & 88 & 88 & 100 & 509 & 84,8 \\
\hline 11 & 98 & 100 & 98 & 100 & 100 & 100 & 596 & 99,3 \\
\hline 12 & 90 & 100 & 100 & 98 & 100 & 100 & 588 & 98 \\
\hline 13 & 89 & 94 & 100 & 100 & 100 & 85 & 568 & 94,7 \\
\hline 14 & 100 & 100 & 96 & 100 & 98 & 100 & 594 & 99 \\
\hline 15 & 100 & 100 & 98 & 100 & 90 & 88 & 576 & 96 \\
\hline Jumlah & 1407 & 1384 & 1431 & 1462 & 1426 & 1461 & 8571 & 1428,6 \\
\hline Rata-rata & 93,8 & 92,3 & 95,4 & 97,5 & 95,1 & 97,4 & 571,4 & $\mathbf{9 5 , 2} \%$ \\
\hline
\end{tabular}

Tabel 5. Rekapitulasi Rata-rata Kelas Aktivitas Belajar Subtema 3

\begin{tabular}{ccc}
\hline Pembelajaran & Rata-rata Kelas Subtema 3 & Keterangan \\
\hline 1 & $78 \%$ & Aktif \\
\hline 2 & $76 \%$ & Aktif \\
\hline 3 & $75,8 \%$ & Aktif \\
\hline 4 & $75,6 \%$ & Aktif \\
\hline 5 & $80,2 \%$ & Sangat Aktif \\
\hline 6 & $78,7 \%$ & Aktif \\
\hline Jumlah & 464,3 & \\
\hline Rata-rata & $\mathbf{7 7 , 4 \%}$ & Aktif \\
\hline
\end{tabular}

Sedangkan untuk nilai sikap peduli lingkungan dinilai saat proses belajar menggunakan modul. Melalui aktivitas yang ada, dapat dilihat seberapa peduli siswa terhadap lingkungan sekitar tempat tinggal. Melalui berbagai model dan strategi siswa diajak untuk mencintai dan peduli terhadap lingkungan tempat tinggalnya. Berikut tabel nilai proses sikap peduli lingkungan.

Tabel 6. Sikap Peduli Lingkungan

\begin{tabular}{|c|c|c|c|c|c|c|c|c|}
\hline \multirow{2}{*}{ No } & \multicolumn{6}{|c|}{ Nilai Sikap Peduli Lingkungan } & \multirow{2}{*}{ Jumlah } & \multirow{2}{*}{ Rata-rata } \\
\hline & $\mathbf{P} 1$ & $\mathbf{P} 2$ & P 3 & $\mathbf{P 4}$ & P 5 & P 6 & & \\
\hline 1 & 4 & 4 & 3 & 4 & 4 & 3 & 22 & 4 \\
\hline 2 & 4 & 4 & 4 & 3 & 3 & 4 & 22 & 4 \\
\hline 3 & 3 & 4 & 2 & 4 & 3 & 3 & 19 & 3 \\
\hline 4 & 2 & 2 & 4 & 4 & 4 & 4 & 20 & 3 \\
\hline 5 & 3 & 3 & 3 & 4 & 4 & 4 & 20 & 3 \\
\hline 6 & 3 & 3 & 3 & 4 & 4 & 3 & 19 & 3 \\
\hline 7 & 4 & 4 & 2 & 2 & 3 & 4 & 19 & 3 \\
\hline 8 & 4 & 3 & 4 & 4 & 4 & 4 & 22 & 4 \\
\hline
\end{tabular}




\begin{tabular}{ccccccccc}
9 & 4 & 4 & 4 & 4 & 4 & 4 & 24 & 4 \\
\hline 10 & 4 & 3 & 3 & 4 & 4 & 3 & 20 & 3 \\
\hline 11 & 2 & 4 & 4 & 3 & 2 & 3 & 18 & 3 \\
\hline 12 & 4 & 4 & 4 & 4 & 4 & 4 & 24 & 4 \\
\hline 13 & 3 & 3 & 3 & 3 & 3 & 4 & 18 & 3 \\
\hline 14 & 3 & 4 & 4 & 4 & 4 & 4 & 23 & 4 \\
\hline 15 & 4 & 4 & 3 & 3 & 3 & 4 & 21 & 4 \\
\hline Jumlah & 51 & 53 & 50 & 54 & 53 & 55 & 311 & 52 \\
\hline Rata-rata & 3 & 4 & 3 & 4 & 4 & 4 & 21 & 3 \\
\hline
\end{tabular}

\section{Keterangan :}

4 Sangat Baik : mencegah kerusakan pada lingkungan sekitarnya dan mengembangkan upaya-upaya untuk memperbaiki kerusakan.

Jika siswa sering memiliki sikap dan tindakan yang selalu berupaya

3 Baik : mencegah kerusakan pada lingkungan sekitarnya dan mengembangkan upaya-upaya untuk memperbaiki kerusakan.

Jika siswa Kadang-kadang memiliki sikap dan tindakan yang selalu

2 Cukup : berupaya mencegah kerusakan pada lingkungan sekitarnya dan mengembangkan upaya-upaya untuk memperbaiki kerusakan.

Jika siswa tidak pernah memiliki sikap dan tindakan yang selalu

1 Kurang : berupaya mencegah kerusakan pada lingkungan sekitarnya dan mengembangkan upaya-upaya untuk memperbaiki kerusakan.

Hasil validasi ahli aspek isi/materi menunjukkan 96,8\% dengan kriteria sangat valid dan dapat digunakan tanpa revisi. Validasi ahli bahasa menunjukkan 90,5\% dengan kriteria sangat valid dan dapat digunakan tanpa revisi. Validasi ahli desaign menunjukkan $80,8 \%$ dengan kriteria sangat valid dan dapat digunakan tanpa revisi. Sedangkan aspek keterterapan guru dan siswa produk modul melalui angket menunjukkan persentase rata-rata 92,5\% dengan kriteria sangat baik dan dapat digunakan tanpa revisi. Sedangkan keefektifan modul dilihat dari dua aspek yaitu hasil belajar dengan persentase rerata 95,2\% menunjukkan pembelajaran tuntas dan aktivitas belajar menunjukkan keterangan aktif dengan persentase $77,4 \%$. Sedangkan nilai sikap peduli lingungan menunjukan persentase $3 \%$ yaitu sikap baik terhadap lingkungan tempat tinggal.

\section{SIMPULAN}

Berdasarkan hasil penelitan dan pengembangan dapat disimpulkan modul berbasis potensi Kabupaten Trenggalek mampu melengkapi bahan ajar yang digunakan oleh guru. Produk modul yang dikembangkan telah memenuhi komponen kelayakan yang diperoleh uji ahli, keterterapan, dan keefektifan. Modul berbasis potensi Kabupaten Trenggalek dapat digunakan sesuai dengan karakteristik siswa dan dapat mengaplikasikan dan membiasakan sikap peduli lingkungan yang terdapat dalam pendidikan karakter melalui pembelajaran yang terdapat dalam modul. 


\section{DAFTAR RUJUKAN}

Ahmadi, I. K., Amri, S., \& Elisah, T. (2012). Mengembangkan pendidikan berbasis keunggulan lokal dalam KTSP. Jakarta: Prestasi Pustaka.

Chrisiana, W. (2005). Upaya penerapan pendidikan karakter bagi mahasiswa (studi kasus di jurusan teknik industri uk petra). Jurnal Teknik Industri, 7(1), 83-90.

Fogarty, R. (1991). The mindfull school: How to integrate the curricula. Paltine: Skyligh Publishing, Inc. Tersedia di www. ascd. org/ASCD/pdf/journals/ed_lead/el_199110_fogarty.pdf.

Gall, M. D., Borg, W. R., \& Gall, J. P. (1996). Educational research: An introduction. Longman Publishing.

Krathwohl, D. R., \& Anderson, L. W. (2009). A taxonomy for learning, teaching, and assessing: A revision of Bloom's taxonomy of educational objectives. Longman.

Kresnawati, N., Wahjoedi, W., \& Sumarmi, S. (2013). Korelasi Kualitas Pembelajaran Geografi dan Hasil Belajar Dengan Sikap Peduli Lingkungan Siswa Kelas XII IPS SMA Negeri 1 Ponorogo.(Tesis). DISERTASI dan TESIS Program Pascasarjana UM.

Prastowo, A. (2013). Pengembangan bahan ajar tematik.

Rozhana, K. M. (2017). Model Problem Based Intruction Berbantuan Mind Mapping Pada Materi Permasalahan Sosial Di Lingkungan Setempat Untuk Meningkatkan Aktivitas Dan Hasil Belajar Siswa Kelas IV SD. Jurnal Pendidikan Dasar Nusantara, 2(2).

Utari, U., \& Degeng, I. N. S. (2016). Pembelajaran tematik berbasis kearifan lokal di sekolah dasar dalam menghadapi Masyarakat Ekonomi Asean (MEA). Jurnal Teori dan Praksis Pembelajaran IPS, 1(1), 39-44.

Wisahati, A. S., \& Santosa, T. (2010). Pendidikan Jasmani Olahraga dan Kesehatan. Pusat Perbukuan Kementrian Pendidikan, Jakarta. 